\title{
UNIVERSITYOF BIRMINGHAM

\section{Threshold photoelectron photoion coincidence spectroscopy and selected ion flow tube reactions of CHF3: comparison of product branching ratios§}

\author{
Parkes, M. A.; Chim, R. Y. L.; Mayhew, C. A.; Mikhailov, V. A.; Tuckett, R. P.
}

DOI:

$10.1080 / 00268970500373429$

Citation for published version (Harvard):

Parkes, MA, Chim, RYL, Mayhew, CA, Mikhailov, VA \& Tuckett, RP 2006, 'Threshold photoelectron photoion coincidence spectroscopy and selected ion flow tube reactions of $\mathrm{CHF}_{3}$ : comparison of product branching ratios§', Molecular Physics, vol. 104, no. 2, pp. 263-272. https://doi.org $310.1080 / 00268970500373429$

Link to publication on Research at Birmingham portal

\section{General rights}

Unless a licence is specified above, all rights (including copyright and moral rights) in this document are retained by the authors and/or the copyright holders. The express permission of the copyright holder must be obtained for any use of this material other than for purposes permitted by law.

- Users may freely distribute the URL that is used to identify this publication.

- Users may download and/or print one copy of the publication from the University of Birmingham research portal for the purpose of private study or non-commercial research.

- User may use extracts from the document in line with the concept of 'fair dealing' under the Copyright, Designs and Patents Act 1988 (?)

- Users may not further distribute the material nor use it for the purposes of commercial gain.

Where a licence is displayed above, please note the terms and conditions of the licence govern your use of this document.

When citing, please reference the published version.

Take down policy

While the University of Birmingham exercises care and attention in making items available there are rare occasions when an item has been uploaded in error or has been deemed to be commercially or otherwise sensitive.

If you believe that this is the case for this document, please contact UBIRA@lists.bham.ac.uk providing details and we will remove access to the work immediately and investigate. 
Threshold photoelectron photoion coincidence spectroscopy and selected ion flow tube reactions of $\mathrm{CHF}_{3}$ : comparison of product branching ratios

M.A. Parkes, R.Y.L. Chim, C.A. Mayhew, V. Mikhailov and R.P. Tuckett*

Mol. Phys., (2006) 104(2), 263-272.

DOI: $10.1080 / 00268970500373429$

This is the author's version of a work that was accepted for publication in Molecular Physics. Changes resulting from the publishing process, such as editing, corrections, structural formatting, and other quality control mechanisms may not be reflected in this document. A definitive version was subsequently published in the reference given above. The DOI number of the final paper is also given above.

Professor Richard Tuckett (University of Birmingham) / July 2011 


\title{
Threshold photoelectron photoion coincidence spectroscopy and selected ion flow tube reactions of $\mathrm{CHF}_{3}$ : comparison of product branching ratios
}

\author{
M. A. Parkes, ${ }^{a}$ R. Y. L. Chim, ${ }^{a}$ C. A. Mayhew, ${ }^{b}$ V. A. Mikhailov, ${ }^{b}$ R. P. Tuckett ${ }^{a,}$ \\ a. School of Chemistry, University of Birmingham, Edgbaston, Birmingham, B15 2TT, U.K. \\ b. School of Physics and Astronomy, University of Birmingham, Edgbaston, Birmingham, B15 2TT, U.K.
}

$\begin{array}{lll}\text { Number of pages : } & 18 \text { (excluding figures and figure captions) } \\ \text { Number of tables : } & 3 & \\ \text { Number of figures : } & 3\end{array}$

In honour of Professor John Simons' 70th birthday Festschrift.

Abstract The threshold photoelectron and threshold photoelectron photoion coincidence spectra of $\mathrm{CHF}_{3}$ in the range $13.5-24.5 \mathrm{eV}$ have been recorded. Ion yields and branching ratios have been determined for the three fragments $\mathrm{CF}_{3}{ }^{+}, \mathrm{CHF}_{2}{ }^{+}$and $\mathrm{CF}^{+}$. The mean kinetic energy releases into fragment ions involving either $\mathrm{C}-\mathrm{H}$ or $\mathrm{C}-\mathrm{F}$ bond cleavage have been measured, and compared with statistical and impulsive models. $\mathrm{CHF}_{3}{ }^{+}$behaves in a non-statistical manner characteristic of the small-molecule limit, with the ground electronic state and low-lying excited states of $\mathrm{CHF}_{3}{ }^{+}$being largely repulsive along the $\mathrm{C}-\mathrm{H}$ and $\mathrm{C}-\mathrm{F}$ coordinates, respectively. The rate coefficients and product ion branching ratios have been measured at 298 $\mathrm{K}$ in a selected ion flow tube for the reactions of $\mathrm{CHF}_{3}$ with a large number of gas-phase cations whose recombination energies span the range 6.3 through $21.6 \mathrm{eV}$. A comparison between the branching ratios from the two experiments, together with an analysis of the threshold photoelectron spectrum of $\mathrm{CHF}_{3}$, shows that long-range charge transfer probably occurs for the $\mathrm{Ar}^{+}$and $\mathrm{F}^{+}$atomic ions whose recombination energies lie above $c a$. $15 \mathrm{eV}$. Below this energy, the mechanism involves a combination of short-range charge transfer and chemical reactions involving a transition state intermediate. 


\section{Introduction}

Fluoroform $\left(\mathrm{CHF}_{3}\right)$ is a major industrial gas which is often used as a replacement for common feedgases, such as $\mathrm{CHBr}_{3}, \mathrm{CHCl}_{3}$ and $\mathrm{CF}_{4}$, in plasma technological applications [1]. All four compounds contribute to global warming via the greenhouse effect, and $\mathrm{CHBr}_{3}$ and $\mathrm{CHCl}_{3}$ are serious ozone depleters in the stratosphere. The lack of $\mathrm{Cl}$ or $\mathrm{Br}$ atoms in $\mathrm{CHF}_{3}$ means that it does not contribute to stratospheric ozone depletion, and the presence of one hydrogen atom means that the tropospheric lifetime of $\mathrm{CHF}_{3}$ is significantly less than that of $\mathrm{CF}_{4}$. The use of $\mathrm{CHF}_{3}$ in plasma technology means that it is important to understand the properties of this molecule under electron and ion impact, pertinent to technological and radiofrequency plasmas, and under vacuum-UV photoexcitation with photons of similar energy. Previous work in this area includes electron impact dissociation [2, 3], electron energy loss spectroscopy [4], vacuumUV photoelectron spectroscopy (PES) [5-8], VUV absorption [9-11], and a positron impact dissociation study [12]. The structure of $\mathrm{CHF}_{3}$ has been determined by microwave spectroscopy [13], and there have been numerous infrared and Raman studies. The interaction of $\mathrm{CHF}_{3}$ with low-energy electrons has been thoroughly reviewed by Christophorou et al. [14]. It is surprising, therefore, there has only been a limited amount of work done on the reaction of $\mathrm{CHF}_{3}$ with gas-phase ions [1,15-19], two of which are anion studies. There has been no measurement of the PES of $\mathrm{CHF}_{3}$ under threshold conditions, no photoionisation mass spectrometric study, nor a study of the fragmentation of state-selected $\mathrm{CHF}_{3}{ }^{+}$using coincidence techniques. In this paper we report a threshold photoelectron photoion coincidence (TPEPICO) study of $\mathrm{CHF}_{3}$ using tunable vacuum-UV photons, complemented by a study of the reactions of $\mathrm{CHF}_{3}$ with a large number of cations in a selected ion flow tube (SIFT).

An additional motivation for such studies is to understand the importance of long-range charge transfer in ion-molecule reactions. We consider the general situation of a cation $\left(\mathrm{A}^{+}\right)$reacting with a neutral molecule (BC), where $\mathrm{BC}$ has a permanent dipole moment. Charge transfer can occur either at long range or at short range. In the long-range mechanism, $\mathrm{A}^{+}$and $\mathrm{BC}$ approach under the influence of their charge-dipole interaction, until at some critical distance $\left(R_{c}\right)$ the $\mathrm{A}^{+}-\mathrm{BC}$ and $\mathrm{A}-\mathrm{BC}^{+}$potential energy curves cross. At this point an electron jump can take place. We have shown [20] that $R_{c}$ depends on the difference in energy between the recombination energy (RE) of $\mathrm{A}^{+}$and the ionisation energy (IE) of $\mathrm{BC}$; the smaller this difference, the larger $R_{c}$. Furthermore, two important factors for a rapid electron transfer and an efficient long-range charge transfer process are a non-zero energy resonance connecting $\mathrm{BC}$ to an electronic state of $\mathrm{BC}^{+}$at the $\mathrm{RE}$ of $\mathrm{A}^{+}$, and the transferring electron comes from a molecular orbital of $\mathrm{BC}$ that is not shielded from the approaching cation. So long as there is some overlap of vibrational wavefunction between $\mathrm{BC}$ and $\mathrm{BC}^{+}$at the $\mathrm{RE}$ of $\mathrm{A}^{+}$, the evidence from similar-sized molecules (e.g. $\mathrm{CF}_{4}[20], \mathrm{CHClF}_{2}$ and $\mathrm{CHCl}_{2} \mathrm{~F}$ [21]) is 
that the magnitude of the photoionisation Franck-Condon factor for BC is not as important as originally thought in determining the efficiency of such a reaction. We note that if this long-range charge transfer mechanism operates, then the branching ratios for fragmentation of $\left(\mathrm{BC}^{+}\right)^{(*)}$, where $(*)$ donates the possibility of $\mathrm{BC}^{+}$being in an excited electronic state, are expected to be independent of how this state is produced. Hence, we would expect similar product branching ratios from the ion-molecule study and from the TPEPICO photoionisation study, assuming the photon energy in the latter experiment matches the RE of $\mathrm{A}^{+}$ in the former.

When long-range charge transfer is unfavourable, $\mathrm{A}^{+}$and $\mathrm{BC}$ move closer together. As their separation decreases, distortion of the potential energy surface of interaction occurs. Eventually, a curve crossing can occur through which efficient charge transfer takes place. This is called short-range charge transfer. As an intermediate complex has formed, a chemical reaction, defined as the breaking and making of new bonds, may, in addition, compete with short-range charge transfer. This means that it is unlikely that the product branching ratios from the ion-molecule and from the TPEPICO experiments will mimic each other. Thus, a comparison of the fragmentation patterns from the SIFT and TPEPICO experiments, together with an analysis of the TPES of BC at the energy of the RE of $\mathrm{A}^{+}$, may indicate which mechanism, be it long-range or short-range, is dominant for the reaction of each cation.

\section{Experimental}

The apparatus used for the TPEPICO study has been described in detail previously [22], the experiments being performed at the Daresbury Synchrotron Radiation Source. The coincidence experiment was performed on beamline 3.1 ( $1 \mathrm{~m}$ Seya-Namika monochromator) operating at a resolution of $0.3 \mathrm{~nm}$, whilst a higher resolution threshold photoelectron spectrum (TPES) was recorded on beamline 3.2 (5 m McPherson monochromator) at a resolution of $0.15 \mathrm{~nm}$. The monochromatised radiation is coupled into the interaction region and its flux is monitored via the fluorescence of a sodium salicylate coated pyrex window. Threshold photoelectrons and fragment cations from the interaction region are extracted in opposite directions by an

electric field of $20 \mathrm{~V} \mathrm{~cm}^{-1}$, and are detected by a channeltron and a pair of microchannel plates, respectively. Both the threshold electron analyser and the time-of-flight mass spectrometer have been described elsewhere [22]. The raw pulses from the detectors are discriminated and are passed to a time-to-digital converter (TDC) mounted in a dedicated PC. The electrons provide a 'start' trigger while the ions provide a 'stop' signal, allowing signals from the same ionisation process to be detected in coincidence. 
With this apparatus, three different spectra can be recorded. Firstly, the TPES spectrum is obtained by recording the threshold electron signal as a function of photon energy. Secondly, a TPEPICO spectrum is obtained by recording the coincidence spectrum continuously as a function of photon energy. The data are recorded as a 3D map of coincidence counts $v s$. ion time of flight $v s$. photon energy. Sections from this map can yield either the time-of-flight mass spectrum at a defined photon energy or the yield of a particular ion. In this mode the resolution of the TOF analyser is set so that all observed fragment ions appear on one single coincidence map; in this case, spectra were recorded over 512 channels at a time resolution of 16 ns to encompass $\mathrm{CF}^{+}$through to $\mathrm{CF}_{3}{ }^{+}$. Thirdly, with a fixed photon energy, high resolution TOF spectra can be produced at the highest resolution of $8 \mathrm{~ns}$. Analysis of the peak shape of the ion fragment can reveal the kinetic energy release into that ion [23,24]. Via conservation of momentum, the mean kinetic energy release, $<\mathrm{KE}>_{\mathrm{T}}$, into the two fragments is obtained. The ratio of $\left\langle\mathrm{KE}>_{\mathrm{T}}\right.$ to the energy available ( $\mathrm{E}_{\text {avail }}$ ) shows what fraction of the energy, $\langle f\rangle_{\mathrm{T}}$, is channelled into translational motion of the two fragments. This value for $\langle f\rangle_{\mathrm{T}}$ can be compared to statistical and impulsive models to indicate the mechanism of dissociation. These models have been reviewed elsewhere [25] and are not discussed here.

The SIFT apparatus has been described in detail elsewhere [26]. Briefly, each reagent ion of interest is produced in a high pressure electron impact ion source containing an appropriate source gas [21]. The cation is injected through a quadrupole mass filter into a flow tube holding ca. 0.5 Torr of high purity (99.997\%) helium as a buffer gas. The neutral reactant of choice is then admitted through an inlet at one of various points down the flow tube. The resultant ionic products are detected using a quadrupole mass spectrometer (VG SXP300). The loss of reagent ion signal, alongside the increase in the various product ion signal(s), is recorded as a function of neutral reactant concentration. The amount of neutral is altered between zero and a concentration that depletes the reactant ion signal by $c a .90 \%$. Since the experiment operates under pseudofirst-order conditions with $\left[\mathrm{A}^{+}\right] \ll[\mathrm{BC}]$, and knowing the reaction length and ion flow velocity [26], a plot of the logarithm of the reagent ion signal vs. neutral molecule concentration allows the rate coefficient to be determined. Rate coefficients with a upper limit of $c a \cdot 10^{-13} \mathrm{~cm}^{3}$ molecule $\mathrm{s}^{-1}$ are too slow be measured in our apparatus. Percentage branching ratios for each product ion are derived from graphs of the relative product ion counts $v s$. neutral molecule concentration, with extrapolation to zero neutral gas flow to allow for the effect of any secondary reactions. This is particularly important for reactions producing $\mathrm{CF}_{3}^{+}$, since this ion reacts with $\mathrm{CHF}_{3}$ (Section 4.2). No allowance has been made in either experiment for mass discrimination effects of the respective ion detectors. This is relatively unimportant in the SIFT experiment, since the branching ratio measurements were made at the lowest possible mass resolution of the quadrupole ion detector when such effects are negligible. In the TPEPICO experiment, there is some evidence that the microchannel plate detectors discriminate in favour of lighter mass ions [27], but the difference between $51 \mathrm{u}$ 
$\left(\mathrm{CHF}_{2}^{+}\right)$and $69 \mathrm{u}\left(\mathrm{CF}_{3}^{+}\right)$, the two major product ions in this study, are relatively small. We therefore quote a conservative error in the branching ratios of either experiment as $\pm 10 \%$ for values greater than $10 \%$, this error increasing for smaller branching ratios. When comparing branching ratios between the two experiments, we believe it is appropriate to propogate these errors. Therefore, agreement within $c a$. $\pm 15 \%$ is acceptable as evidence for possible long-range charge transfer.

\section{Energetics}

The fragment ions observed in the dissociative photoionisation of $\mathrm{CHF}_{3}$ between 13 and $25 \mathrm{eV}$ are $\mathrm{CF}_{3}{ }^{+}$, $\mathrm{CHF}_{2}{ }^{+}$and $\mathrm{CF}^{+}$(Section 4.1.2). We note that the parent ion is not observed, nor (surprisingly) fragments caused by cleavage of two bonds. The energetics of the possible photodissociation channels of $\mathrm{CHF}_{3}$ to produce these three fragment ions are listed in table 1. The appearance energies $\left(\mathrm{AE}_{298}\right)$ of each fragment are measured from the first observation of signal above the background noise. For the major product ions, defined as a fragment formed by breaking of a single bond, the $\mathrm{AE}_{298}$ values (column 2) are converted into an upper limit for $\Delta_{r} H_{298}^{0}$ (column 3) for the appropriate unimolecular reaction using the procedure of Traeger and McLoughlin [28], a procedure described in detail elsewhere [29]. The vibrational frequencies of the two major fragment ions were not available in their entirety, therefore they were estimated from the isoelectronic molecules $\mathrm{BF}_{3}$ and $\mathrm{BHF}_{2}$. The enthalpies of formation were taken from standard reference sources [30,31], apart from values for $\mathrm{CF}_{3}^{+}\left(406 \mathrm{~kJ} \mathrm{~mol}^{-1}\right)$ [32] and $\mathrm{CHF}_{2}^{+}\left(604 \mathrm{~kJ} \mathrm{~mol}^{-1}\right)$ [33]. For the SIFT study (Table 3), apart from these standard sources, we use enthalpies of formation which are quoted in the footnote to this Table.

\section{Results}

\subsection{Photon-induced reactions of $\mathrm{CHF}_{3}$}

\subsubsection{Threshold photoelectron spectrum}

The TPES of $\mathrm{CHF}_{3}$ was recorded from $13.5-24.5 \mathrm{eV}$ at a resolution of $0.15 \mathrm{~nm}$ (Fig. 1a). The onset of ionisation is $13.85 \pm 0.05 \mathrm{eV}$, in excellent agreement with Brundle et al. [5]. The valence molecular orbitals of $\mathrm{CHF}_{3}$ are labelled in $\mathrm{C}_{3 \mathrm{v}}$ symmetry $\ldots .\left(4 \mathrm{a}_{1}\right)^{2}\left(5 \mathrm{a}_{1}\right)^{2}(3 \mathrm{e})^{4}(4 \mathrm{e})^{4}(5 \mathrm{e})^{4}\left(1 \mathrm{a}_{2}\right)^{2}\left(6 \mathrm{a}_{1}\right)^{2}[5,14]$, where the numbering of the orbitals includes the carbon and fluorine $1 \mathrm{~s}$ core orbitals. The $6 \mathrm{a}_{1} \mathrm{HOMO}$ is essentially $\sigma_{\mathrm{C}-\mathrm{H}}$ bonding, the $1 \mathrm{a}_{2}, 5 \mathrm{e}$ and $4 \mathrm{e}$ orbitals are $\mathrm{F} 2 \mathrm{p} \pi$ non-bonding, $3 \mathrm{e}$ is $\sigma_{\mathrm{C}-\mathrm{F}}$ bonding, and $5 \mathrm{a}_{1}$ is a mixture of $\sigma_{\mathrm{C}-\mathrm{H}}$ and $\sigma_{\mathrm{C}-\mathrm{F}}$ bonding in character [5]. The $4 \mathrm{a}_{1}$ orbital at $c a, 24.5 \mathrm{eV}$ has a small partial photoionisation cross section, and is also $\sigma_{\mathrm{C}-\mathrm{H}}$ bonding in character [5]. The vertical ionisation energies (VIE) of the first five peaks are 14.81 $\left(\widetilde{X}^{2} \mathrm{~A}_{1}\right), 15.57\left(\widetilde{A}^{2} \mathrm{~A}_{2}\right), 16.35\left(\widetilde{B}^{2} \mathrm{E}\right), 17.28\left(\widetilde{C}^{2} \mathrm{E}\right)$ and $20.74\left(\widetilde{D}^{2} \mathrm{E}\right.$ and $\left.\widetilde{E}^{2} \mathrm{~A}_{1}\right) \mathrm{eV}$, respectively. These values are in excellent agreement with previous studies using He I radiation [5-8]. At this resolution, clearly- 
resolved vibrational structure is only observed in the overlapped $\widetilde{D} / \widetilde{E}$ band at $20.74 \mathrm{eV}$, where a long progression in the $v_{6}\left(a_{1}\right)$ mode, average spacing $0.056 \mathrm{eV}$ or $455 \mathrm{~cm}^{-1}$, can be seen. In addition, a broad band is observed centred at $19.22 \mathrm{eV}$ under threshold conditions which has not been detected before. This band arises through autoionisation of a Rydberg state of $\mathrm{CHF}_{3}$ at the same energy, producing a threshold photoelectron. In a recent absorption study at a resolution of $0.08 \mathrm{~nm}$ [11], a peak is observed at $19.19 \mathrm{eV}$ and assigned to the $\left(4 \mathrm{a}_{1}\right)^{-1} 3 \mathrm{~s}$ Rydberg state, whilst Wu et al. [9] at a slightly inferior resolution assign this peak to the $\left(3 \mathrm{e} \text { or } 5 \mathrm{a}_{1}\right)^{-1} 3 \mathrm{~d}$ transition. In the context of interpreting the ion-molecule results (Section 5), the

Franck-Condon regions of the $\widetilde{A}, \widetilde{B}$ and $\widetilde{C}$ states of $\mathrm{CHF}_{3}{ }^{+}$, where the electron is removed from a $\mathrm{F} 2 \mathrm{p} \pi$ non-bonding orbital of $\mathrm{CHF}_{3}$ unshielded from the approaching cation, encompass the range $c a$. 15-18 eV. By contrast, in the range from the onset of ionisation up to $15 \mathrm{eV}$ and for energies greater than $18 \mathrm{eV}$, the electron is removed from a $\mathrm{C}$-H or $\mathrm{C}-\mathrm{F} \sigma$-bonding orbital, where the fluorine atoms may cause some shielding for efficient long-range electron transfer to the approaching cation.

\subsubsection{Scanning TPEPICO spectrum}

A scanning-energy TPEPICO spectrum was recorded for $\mathrm{CHF}_{3}$ from $13.5-24.5 \mathrm{eV}$ with an optical resolution of $0.3 \mathrm{~nm}$ and a TOF resolution of $16 \mathrm{~ns}$. Three fragment cations, $\mathrm{CF}_{3}{ }^{+}, \mathrm{CHF}_{2}{ }^{+}$and $\mathrm{CF}^{+}$, were observed, but the parent ion was not detected. The design of our TOF mass spectrometer means it can sometimes be difficult to determine the number of hydrogen atoms in a fragment ion [22]. However, with a resolution as high as $16 \mathrm{~ns}$, we can state with confidence that these three fragment ions contain no contributions from $\mathrm{CHF}_{3}{ }^{+}, \mathrm{CF}_{2}{ }^{+}$and $\mathrm{CHF}^{+}$, respectively. The parent ion has never been observed unambiguously in previous electron or photon impact studies of $\mathrm{CHF}_{3}$, although electron impact studies observe $\mathrm{CF}_{2}^{+}$and $\mathrm{CHF}^{+}[2,3]$. In a recent photoion-fluorescence coincidence study of electron-impact-excited $\mathrm{CHF}_{3}$, Furuya et al. [34] also observe $\mathrm{CF}_{2}{ }^{+}$on the shoulder of the $\mathrm{CHF}_{2}{ }^{+}$peak, but the electron energy is relatively high, $120 \mathrm{eV}$, and the presence of $\mathrm{CF}_{2}{ }^{+}$is only determined via simulation.

Fragment ion yields abstracted from the 3D map are shown in Figure $1 \mathrm{~b} . \mathrm{CF}_{3}{ }^{+}$is observed at the onset of ionisation of $\mathrm{CHF}_{3}, 13.85 \pm 0.05 \mathrm{eV}$, and is the only charged product produced from the ground state of $\mathrm{CHF}_{3}{ }^{+}$. The breaking of the $\mathrm{C}-\mathrm{H}$ bond, and hence loss of an hydrogen atom, can be explained by the HOMO of $\mathrm{CHF}_{3}$ being essentially $\sigma_{\mathrm{C}-\mathrm{H}}$ bonding and the assumption that intramolecular vibrational redistribution (IVR) is slow. The appearance energy for formation of $\mathrm{CHF}_{2}{ }^{+}$is $15.03 \pm 0.05 \mathrm{eV}$, and is the major fragment produced from the $\widetilde{A}, \widetilde{B}$ and $\widetilde{C}$ states of $\mathrm{CHF}_{3}{ }^{+}$. We note that these states arise from electron removal from F 2 p $\pi$ non-bonding orbitals so, unless IVR is now very rapid, breaking of a C-F bond is to be expected from these states. The $\mathrm{CF}^{+}$fragment has a weak threshold at $18.9 \pm 0.2 \mathrm{eV}$ which probably corresponds to 
production of the Rydberg state of $\mathrm{CHF}_{3}$, with a VIE of $19.22 \mathrm{eV}$, described in Section 4.1.1. The $\mathrm{CF}^{+}$signal then rises rapidly for $\mathrm{h} v>20 \mathrm{eV}$, and has a maximum at $20.6 \mathrm{eV}$, these values corresponding exactly to the adiabatic and vertical IEs of the blended $\widetilde{D}{ }^{2} \mathrm{E}$ and $\widetilde{E}^{2} \mathrm{~A}_{1}$ states of $\mathrm{CHF}_{3}{ }^{+}$.

These data are collected in Table 1. For the $\mathrm{CF}_{3}^{+}$and $\mathrm{CHF}_{2}^{+}$fragments the appearance energies at $298 \mathrm{~K}$,

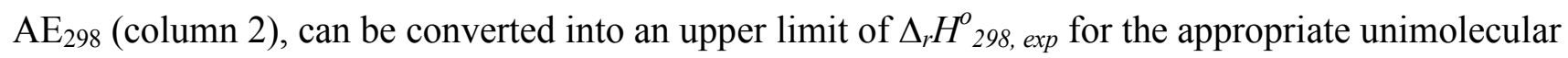
reaction (column 3) via the procedure of Traeger and McLoughlin [28]. Calculated values for $\Delta_{r} H_{298}^{o}$ are shown in column 4, and these values can be converted into calculated $\mathrm{AE}_{298}$ values (column 5). Comparing values for the enthalpies of reaction, $\mathrm{CHF}_{3} \rightarrow \mathrm{CF}_{3}{ }^{+}+\mathrm{H}+\mathrm{e}^{-}$is $0.27 \mathrm{eV}$ more endothermic than the calculated value. Thus the onset of $\mathrm{CF}_{3}{ }^{+}$does not relate to its thermochemical threshold, but to the energy of the ground state of $\mathrm{CHF}_{3}^{+}$which is probably repulsive along the dissociative $\mathrm{C}-\mathrm{H}$ coordinate. The same argument holds true for the production of $\mathrm{CHF}_{2}^{+}+\mathrm{F}+\mathrm{e}^{-}$where the difference in endothermicities in now larger, $0.84 \mathrm{eV}$.

Thus the $\widetilde{A}, \widetilde{B}$ and $\widetilde{C}$ states of $\mathrm{CHF}_{3}{ }^{+}$are probably repulsive along the $\mathrm{C}-\mathrm{F}$ coordinate, and dissociate stateselectively to $\mathrm{CHF}_{2}^{+}+\mathrm{F}$. $\mathrm{CHF}_{3}{ }^{+}$is therefore behaving non-statistically in the small-molecule limit [22]. The method of converting $\mathrm{AE}_{298}$ into an upper limit of $\Delta_{r} H_{298 \text {, exp }}^{o}$ is not appropriate for fragment ions in which more than one bond breaks. With this proviso, we comment that the onset of $\mathrm{CF}^{+}$at $18.9 \mathrm{eV}$ lies $c a .2 \mathrm{eV}$ above its corresponding calculated threshold, noting that on energetic grounds $\mathrm{CF}^{+}$can only form with $\mathrm{HF}+$ $\mathrm{F}$ as accompanying neutral partners. It appears that $\mathrm{CF}^{+}$relates to state-selected dissociation of both the autoionising Rydberg state of $\mathrm{CHF}_{3}$ at $19.22 \mathrm{eV}$ and to the $\widetilde{D}$ and $\widetilde{E}$ states of the parent ion.

\subsubsection{Fixed energy TPEPICO spectra}

Fixed energy spectra were recorded with a TOF resolution of $8 \mathrm{~ns}$ for $\mathrm{CF}_{3}{ }^{+}$at $14.76 \mathrm{eV}$ and for $\mathrm{CHF}_{2}^{+}$at 16.35 and $17.36 \mathrm{eV}$, representing the VIEs of the $\widetilde{X}, \widetilde{B}$ and $\widetilde{C}$ states of $\mathrm{CHF}_{3}{ }^{+}$, respectively. Mean translational kinetic energy releases, $\langle\mathrm{KE}\rangle_{\mathrm{T}}$, were obtained from each of these spectra as described elsewhere [23,24]. Briefly, for each TPEPICO-TOF spectrum a small basis set of peaks, each with a discrete energy release $\varepsilon_{t}$ is computed, and assigned a probability. The discrete energies are given by $\varepsilon_{t}(n)=$ $(2 n-1)^{2} \Delta E$, where $n=1,2,3,4 \ldots . \Delta E$ depends on the statistical quality of the data ; the higher the signal-tonoise ratio, the lower $\Delta E$ and the higher $n$ can be set to obtain the best fit. Each computed peak in the kinetic energy release distribution spans the range $4(n-1)^{2} \Delta E$ to $4 n^{2} \Delta E$, centred at $\varepsilon_{t}(n)+\Delta E$. The reduced probability of each discrete energy, $\mathrm{P}\left(\varepsilon_{t}\right)$, is varied by linear regression to minimise the least-squared errors between the simulated and experimental TOF peak. From the basis set of $\varepsilon_{t}$ and $\mathrm{P}\left(\varepsilon_{t}\right),<\mathrm{KE}>_{\mathrm{T}}$ is easily 
determined. The analysis can accommodate a range of isotopes in the daughter ion, but this facility is clearly not needed in this $\mathrm{CHF}_{3}^{+}$project.

Figure 2 shows the TOF spectrum for $\mathrm{CHF}_{2}^{+}$at $17.36 \mathrm{eV}$, the fit to the data, and the agreement is excellent. Table 2 lists the experimental $\langle\mathrm{KE}\rangle_{\mathrm{T}}$ and $\langle\beta\rangle_{\mathrm{T}}$ values, as well as the calculated impulsive and statistical $\langle\beta\rangle_{\mathrm{T}}$ values. Without overinterpreting this data, there is clear indication that the $\widetilde{B}$ and $\widetilde{C}$ states of $\mathrm{CHF}_{3}^{+}$ dissociate non-statistically by cleavage of a C-F bond, with a value for $\left\langle\beta_{\mathrm{T}}\right.$ close to the dynamical, impulsive limit. The ground state of $\mathrm{CHF}_{3}{ }^{+}$also seems to dissociate by $\mathrm{C}-\mathrm{H}$ bond cleavage via a mechanism that has a significant impulsive component. Both these observations are consistent with the yield data for these two ions described in Section 4.1.2.

\subsection{Bimolecular cation-induced reactions of $\mathrm{CHF}_{3}$}

\subsubsection{Rate coefficients}

Reactions between a series of ions, with a range of recombination energies (RE) from $6.27-21.56 \mathrm{eV}$, with $\mathrm{CHF}_{3}$ were studied using the SIFT technique. For each reaction a second order rate coefficient, $k_{\text {exp }}$, was measured, and a value calculated, $k_{\text {calc }}$, using modified-average dipole orientation (MADO) theory [37]. This theory is based on the classical Langevin model [38,39] plus a contribution from the permanent dipole moment of $\mathrm{CHF}_{3}$. To calculate the MADO rate coefficient, values for both the dipole moment (1.65 D) and the polarisability volume $\left(3.15 \times 10^{-30} \mathrm{~m}^{3}\right)$ of $\mathrm{CHF}_{3}$ were required [14]. Data for $k_{\text {exp }}$ and $k_{\text {calc }}$ is shown in column 2 of Table 3 . The efficiency of the reaction is defined as $k_{\text {exp }} / k_{\text {calc. }}$.

For those cations whose $\mathrm{RE}$ is above the $\mathrm{IE}\left(\mathrm{CHF}_{3}\right), 13.85 \mathrm{eV}, k_{\text {exp }}$ is very similar to $k_{\text {calc }}$, implying that these are efficient reactions which occur upon nearly every collision. The one exception is $\mathrm{Kr}^{+}(\mathrm{RE}=14.00 \mathrm{eV})$, just above the IE $\left(\mathrm{CHF}_{3}\right)$, where the efficiency is only 0.5. There is no obvious correlation between efficiency of reaction and RE of the cation. For cations with $\mathrm{RE}$ below the IE $\left(\mathrm{CHF}_{3}\right)$, only seven of the seventeen collision systems studied exhibited any reactivity. Of these seven, all but $\mathrm{O}^{+}$and $\mathrm{OH}^{+}$have $k_{\exp }$ which is somewhat lower than $k_{\text {calc, }}$ and for $\mathrm{CO}_{2}{ }^{+}$and $\mathrm{CF}_{3}{ }^{+}$the reaction efficiency falls to $c a \cdot 0.25$. Energetics alone cannot explain the observed values of $k_{\text {exp. }}$. For example, $\mathrm{O}^{+}$and $\mathrm{CO}_{2}{ }^{+}$differ in $\mathrm{RE}$ by only $0.16 \mathrm{eV}$, yet the former reacts with unity efficiency whereas the latter has an efficiency less than 0.25 . This suggests that steric effects for this group of reactions may be important. Such reactions can only occur via a short-range intermediate (Section 1), so it is not surprising that such effects may play an important role.

\subsubsection{Branching Ratios}


The branching ratios of the product cations are also measured in the SIFT experiment, data shown in column 3 of Table 3. We note that the resolution of the quadrupole mass spectrometer, when used for product ion assignment, is better than $1 \mathrm{u}$, therefore there can be no ambiguity in the assignment of product cations. The parent ion, $\mathrm{CHF}_{3}^{+}$, is not observed, and the three major product ions are $\mathrm{CF}_{3}^{+}, \mathrm{CHF}_{2}^{+}$and $\mathrm{CF}^{+}$. The two exceptions are that the reaction of $\mathrm{H}_{2} \mathrm{O}^{+}(\mathrm{RE}=12.56 \mathrm{eV})$ produces exclusively $\mathrm{CF}_{2} \mathrm{OH}^{+}$, and there is a small yield of $\mathrm{CF}_{2}^{+}(15 \%)$ for the reaction of $\mathrm{Ne}^{+}$, the ion with highest $\mathrm{RE}, 21.56 \mathrm{eV}$, studied. Thus the SIFT and TPEPICO experiments detect predominantly the same cationic products.

Columns 4 and 5 of Table 3 present proposed neutral products and associated enthalpies of reaction at $298 \mathrm{~K}$. The proposed pathways are those which are both chemically feasible and are the mosr exothermic. For nearly all the reactions studied, there is an exothermic pathway, consistent with an experimental rate

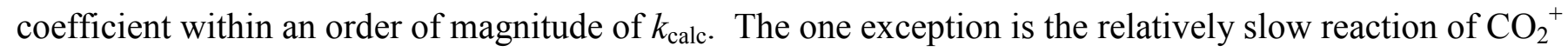
with $\mathrm{CHF}_{3}$ producing $\mathrm{CHF}_{2}^{+}(55 \%)$, where both possible neutral channels $\left(\mathrm{FOCO}\right.$ and $\left.\mathrm{F}+\mathrm{CO}_{2}\right)$ are mildly endothermic. Previous work has highlighted how entropic effects can drive reactions which are enthalpically unfavourable [40], and we note that only a relatively small value for $\Delta_{\mathrm{r}} S^{o}{ }_{298}\left(\mathrm{ca} .30 \mathrm{~J} \mathrm{~mol}^{-1} \mathrm{~K}^{-1}\right)$ would be needed to overcome the endothermicity of the former channel. It should also be noted that, ignoring any entropic effects, the reaction of $\mathrm{Kr}^{+}$with $\mathrm{CHF}_{3}$ to produce the minor product, $\mathrm{CHF}_{2}^{+}(16 \%)$, is only exothermic for $\mathrm{Kr}^{+}$in its excited ${ }^{2} \mathrm{P}_{1 / 2}$ spin-orbit state.

Two further points can be made. First, the cations $\mathrm{CF}_{\mathrm{x}}^{+}(\mathrm{x}=1-3)$ all react with $\mathrm{CHF}_{3}^{+}$with efficiencies between $c a$. 0.3-0.8, despite all having a RE less than $\mathrm{IE}\left(\mathrm{CHF}_{3}\right)$. The only product cation for all three reactions is $\mathrm{CHF}_{2}{ }^{+}$, and therefore $\mathrm{F}^{-}$transfer from $\mathrm{CHF}_{3}$ to produce neutral $\mathrm{CF}_{\mathrm{x}+1}$ is the driving force. Second, a comparison between the products from the $\mathrm{Kr}^{+}{ }^{2} \mathrm{P}_{3 / 2}(\mathrm{RE}=14.00 \mathrm{eV})$ and $\mathrm{CO}^{+}(\mathrm{RE}=14.01 \mathrm{eV})$ reactions is revealing. Both cations have $\mathrm{REs}$ greater then $\mathrm{IE}\left(\mathrm{CHF}_{3}\right)$, with both reactions having relatively high efficiency. Yet the ratio of the products $\mathrm{CHF}_{2}^{+}$and $\mathrm{CF}_{3}^{+}$changes from 0.2 for $\mathrm{Kr}^{+}$to 32 for $\mathrm{CO}^{+}$. This point is discussed further in Section 5.

There have been relatively few studies of the reactivity of $\mathrm{CHF}_{3}$ with positive ions, and very surprisingly none, to our knowledge, in a selected ion flow tube. The reaction of $\mathrm{CF}_{3}{ }^{+}$with $\mathrm{CHF}_{3}$ has been studied using a crossed beam electrostatic trapping cell at a range of collision energies [1], the rate coefficient was not measured but the ionic products were. Our results do not agree, as Peko et al. observe the products $\mathrm{CF}^{+}$, $\mathrm{CF}_{3}{ }^{+}$and $\mathrm{CHF}_{2}{ }^{+}$, whereas we observe only $\mathrm{CHF}_{2}{ }^{+}$. The discrepancy may be due to the high collisional energy used in their study. Pabst et al. [15] studied the reaction of $\mathrm{CHF}_{3}$ with fragment ions produced from electron impact ionisation of $\mathrm{CHF}_{3}$ under relatively high pressure conditions. They observed the same 
fragments from electron impact as we observe from our photon-induced study (Section 4.1), but in addition they observed $\mathrm{CF}_{2}{ }^{+}, \mathrm{F}^{+}$and the parent ion. However, these three ions occurred only as very small percentage yields, especially $\mathrm{CHF}_{3}{ }^{+}(0.5 \%)$. We note that the ions in the study of Pabst et al. were generated at high electron impact energies of 150-200 eV, compared to photon energies of 13-25 eV in our TPEPICO study. The rates of the reactions of $\mathrm{CF}_{3}{ }^{+}$and $\mathrm{F}^{+}$with $\mathrm{CHF}_{3}$ with are in fairly good agreement with our measurements, but their rates for the reaction of $\mathrm{CF}_{2}^{+}$and $\mathrm{CF}^{+}$with $\mathrm{CHF}_{3}$ are much lower. Chau and Bowers [16] used the ion cyclotron resonance technique to study the reactions of $\mathrm{CHF}_{3}$ with the rare gas ions and $\mathrm{N}_{2}^{+}$, $\mathrm{CO}^{+}, \mathrm{CO}_{2}^{+}$and $\mathrm{N}_{2} \mathrm{O}^{+}$. They were unable to measure product distributions but commented that charge transfer dominates over chemical reaction channels. The majority of the rates they measured are in good agreement to ours. Jiao et al. [17] used Fourier Transform mass spectrometry to study the reactions of $\mathrm{Ar}^{+}$, $\mathrm{CF}_{2}{ }^{+}$and $\mathrm{CF}_{3}{ }^{+}$with $\mathrm{CHF}_{3}$. They measure rate coefficients which are much lower than ours, but their product yields are similar.

\section{Comparison between TPEPICO and SIFT data}

Figure 3 shows the branching ratios from the TPEPICO and SIFT studies as a function of energy. The former appear as continuous graphs, whereas the latter appear as data points at defined RE values of the ions. As described in Section 1, a comparison of the branching ratios may indicate the mechanism in operation for the cation reactions. Only seven out of the twenty four ions studied have REs greater than IE $\left(\mathrm{CHF}_{3}\right)$, so it is only for these seven reactions that long-range charge transfer is possible. Of these seven ions, the four with $\mathrm{RE}>15 \mathrm{eV}$ show differing behaviour when comparing branching ratios to the photon-induced study. For $\mathrm{Ar}^{+}, \mathrm{F}^{+}$and $\mathrm{Ne}^{+}$the agreement between data from the two experiments is particularly good, well within the $15 \%$ error that we discussed in Section 2 as acceptable evidence for long-range charge transfer. For $\mathrm{N}_{2}^{+}$ there is a significant difference, a ratio of $48 \% \mathrm{CHF}_{2}{ }^{+}$to $52 \% \mathrm{CF}_{3}{ }^{+}$in the ion-molecule reaction to be compared with $68 \% \mathrm{CHF}_{2}{ }^{+}$to $32 \% \mathrm{CF}_{3}{ }^{+}$in the TPEPICO experiment at a photon energy of $15.58 \mathrm{eV}$. For $\mathrm{N}_{2}{ }^{+}, \mathrm{Ar}^{+}$and $\mathrm{F}^{+}$there is a significant Franck-Condon intensity in the TPES (Fig. 1a) at the RE of these three ions and the electron is removed from an unshielded F $2 \mathrm{p} \pi$ molecular orbital, whereas at the $\mathrm{RE}_{\text {of }} \mathrm{Ne}^{+}$, $21.56 \mathrm{eV}$, the Franck-Condon activity is low and the electron is removed from a mixture of $\sigma_{\mathrm{C}-\mathrm{H}}$ and $\sigma_{\mathrm{C}-\mathrm{F}}$ shielded orbitals.

In Section 1, we described experiments [20,21] that suggested that an energy resonance and the transfer of an unshielded electron were sufficient criteria for long-range charge transfer to occur ; an appreciable Franck-

Condon vibrational overlap factor between $\mathrm{BC}_{\mathrm{v}=0}$ and $\left(\mathrm{BC}^{+}\right)^{(*)}$, was not necessary. The evidence from these reactions with $\mathrm{CHF}_{3}$ is not so clear. For $\mathrm{N}_{2}{ }^{+}$, despite all three criteria being satisfied, the branching ratio 
agreement is poor, suggesting that long-range charge transfer may not be the dominant mechanism. For Ar all three criteria are satisfied, and the agreement between branching ratios is excellent ; long-range charge transfer is apparently dominant. We note that, despite only a small difference between the RE of $\mathrm{N}_{2}^{+}$and $\mathrm{Ar}^{+}, 0.18 \mathrm{eV}$, the branching ratios from the two SIFT experiments are very different. We are unable to explain this surprising result, other than state the obvious that $\mathrm{N}_{2}^{+}$is molecular whereas $\mathrm{Ar}^{+}$is atomic. For $\mathrm{F}^{+}$, there is a small discrepancy between the branching ratios of the two experiments, in that $\mathrm{CHF}_{2}^{+}(100 \%)$ is the only observed product ion, whereas the TPEPICO experiment at $17.42 \mathrm{eV}$ photon energy produces $\mathrm{CHF}_{2}^{+}(93 \%)$ and $\mathrm{CF}_{3}^{+}(7 \%)$. However, the $\mathrm{F}^{+}$signal was very weak, and it is possible that we did not have the sensitivity to observe the $\mathrm{CF}_{3}{ }^{+}$channel. It seems likely that long-range charge transfer is dominant. For $\mathrm{Ne}^{+}$, the RE of $21.56 \mathrm{eV}$ corresponds to the very edge of the Franck-Condon region of the $\widetilde{D} / \widetilde{E}$ states of $\mathrm{CHF}_{3}{ }^{+}$, and the electron is removed from a shielded orbital. Despite the excellent agreement between the branching ratio data, therefore, we suggest that $\mathrm{Ne}^{+}$charges transfers with $\mathrm{CHF}_{3}$ via a short-range intermediate. We note, however, that any judgements on how good agreement between branching ratios needs to be, and what constitutes an appreciable Franck-Condon factor are subjective. We have imposed, somewhat arbitrarily, an agreement within $15 \%$ in the branching ratios as evidence for long-range charge transfer, whilst the detection of an energy resonance with very low Franck-Condon factor depends upon the sensitivity of the electron analyser.

For the three ions with RE in the range 13.9-15.0 $\left(\mathrm{Kr}^{+}, \mathrm{CO}^{+}\right.$and $\left.\mathrm{N}^{+}\right)$, there is significantly poorer agreement between the branching ratios from the two experiments. Indeed, for $\mathrm{CO}^{+}$there is total disagreement in that the bimolecular chemical reaction produces $\mathrm{CHF}_{2}^{+}(97 \%)$ as its main product whereas the photon-induced reaction produces $\mathrm{CF}_{3}^{+}$(ca. 90\%). The agreement of the branching ratios for $\mathrm{N}^{+}(\mathrm{RE}=14.53 \mathrm{eV})$ is poor, the discrepancy for $\mathrm{CF}_{3}^{+}$and $\mathrm{CHF}_{2}^{+}$yields being greater than a factor of two. Thus for $\mathrm{CO}^{+}$and $\mathrm{N}^{+}$long-range charge transfer cannot be the preferred reaction mechanism. We note that in each case the electron would have to transfer from the highest occupied molecular orbital of $\mathrm{CHF}_{3}$, a $\sigma_{\mathrm{C}-\mathrm{H}}$ bonding orbital which will be shielded by three bulky fluorine atoms. The data points for $\mathrm{Kr}^{+}$are in better agreement, within 10-15\% of the photon-induced branching ratios, this being true at the energies of both of its spin-orbit components, ${ }^{2} \mathrm{P}_{3 / 2}$ at 14.00 and ${ }^{2} \mathrm{P}_{1 / 2}$ at $14.67 \mathrm{eV}$. As stated earlier, $\mathrm{CHF}_{2}^{+}(16 \%)$, only becomes energetically allowed if $\mathrm{Kr}^{+}$ exists in its excited spin-orbit state (Table 3). Unfortunately, we are unable to determine how thermalised $\mathrm{Kr}^{+}$is in the SIFT apparatus.

\section{Conclusions}


The threshold photoelectron and threshold photoelectron photoion coincidence spectrum of $\mathrm{CHF}_{3}$ in the range $13.5-24.5 \mathrm{eV}$ have been recorded. Ion yields and branching ratios have been determined for the three fragments produced. No parent ion has been observed, the lowest-energy fragment is $\mathrm{CF}_{3}{ }^{+}$, and as the photon energy increases first $\mathrm{CHF}_{2}^{+}$and then $\mathrm{CF}^{+}$are formed. The mean kinetic energy releases into fragment ions involving one bond cleavage have been measured and compared with statistical and impulsive models. Our work has shown that $\mathrm{CHF}_{3}{ }^{+}$behaves in a non-statistical manner characteristic of the smallmolecule limit, with the ground state and low-lying excited states of $\mathrm{CHF}_{3}{ }^{+}$being largely repulsive along the $\mathrm{C}-\mathrm{H}$ and C-F coordinates, respectively. The rate coefficients and branching ratios have been measured at 298 $\mathrm{K}$ for the reactions of $\mathrm{CHF}_{3}$ with $\mathrm{H}_{3} \mathrm{O}^{+}, \mathrm{CF}_{\mathrm{n}}^{+}(\mathrm{n}=1-3), \mathrm{SF}_{\mathrm{x}}^{+}(\mathrm{x}=1-5), \mathrm{NO}^{+}, \mathrm{O}_{2}^{+}, \mathrm{Xe}^{+}, \mathrm{H}_{2} \mathrm{O}^{+}, \mathrm{N}_{2} \mathrm{O}^{+}, \mathrm{OH}^{+}, \mathrm{O}^{+}$, $\mathrm{CO}_{2}{ }^{+}, \mathrm{Kr}^{+}, \mathrm{CO}^{+}, \mathrm{N}^{+}, \mathrm{N}_{2}{ }^{+}, \mathrm{Ar}^{+}, \mathrm{F}^{+}$and $\mathrm{Ne}^{+}$. Comparison with theory shows that for reactions where charge transfer is exothermic, i.e. $\mathrm{RE}$ (ion) $>\mathrm{IE}\left(\mathrm{CHF}_{3}\right)$, most of the reactions occur efficiently, i.e. $k_{\mathrm{exp}} \approx k_{\mathrm{calc}}$. For reactions at lower energies, the efficiency can be significantly reduced. Comparisons between TPEPICO and SIFT branching ratios, together with an analysis of the TPES of $\mathrm{CHF}_{3}$, show that long-range charge transfer probably occurs for the $\mathrm{Ar}^{+}$and $\mathrm{F}^{+}$atomic ions with recombination energies above $c a .15 \mathrm{eV}$. The importance or otherwise of an appreciable Franck-Condon factor for the neutral molecule, $\mathrm{CHF}_{3}$, at the RE of the ion is unclear. Below $15 \mathrm{eV}$, a combination of short-range charge transfer and chemical reactions take place.

\section{Acknowledgements}

We thank Drs. Ken Boyle, Gary Jarvis and Weidong Zhou for help with collection of data. We are also grateful for the assistance of Dr. Chris Howle and a critical reading of the manuscript. We thank EPSRC and the staff at CCLRC Daresbury Laboratory, especially Dr David Shaw, for grants (GR/M42974 and GR/S21557) and help, respectively. Michael Parkes and Ray Chim thank the University of Birmingham for Studentships.

\section{References}

1. Peko, B.L., Champion, R.L., Rao, M.V.V.S., and Olthoff, J.K., 2002 J. Appl. Phys., $92,1657$.

2. Torres, I., Martínez, R., and Castaño, F., 2002, J. Phys. B, 35, 2423.

3. Goto, M., Nakamura, K., Toyodo, H., and Sugai, H., 1994, Jpn. J. Appl. Phys, 33, 3602.

4. Ying, J.F., and Leung, K.T., 1995, Phys. Rev. A, 53, 1476,

5. Brundle, C.R., Robin, M.B., and Basch, H., 1970, J. Chem. Phys., 53, 2196.

6. Pullen, B.P., Carlson, T.A., Moddeman, W.E., Schweitzer, G.K., Bull, W.E., and Grimm, F.A., 1970, J. Chem. Phys, 53, 768.

7. Potts, A.W., Lempka, H.J., Streets, D.G., and Price, W.C., 
1970, Philos. Trans. R. Soc. London A, 268, 59.

8. Carlson, T.A., and White, R.M., 1972, Faraday Dissc. Chem. Soc., 54, 104.

9. Wu, C.Y.R., Lee, L.C., and Judge, D.L., 1979, J. Chem, Phys, 71, 5221.

10. Sauvageau, P., Gilbert, R., Berlow, P.P., and Sandorfy, C., 1979, J. Chem. Phys., 59, 762.

11. Ali, S., and Tuckett, R.P., 2005, in preparation.

12. Moxom, J., Schrader, D.M., Laricchia, G., Xu, J., and Hulett, L.D., 2000, Phys. Rev. A, 62, 52708.

13. Gazzoli, G., Cludi, L., Cotti, G., Dore, L., Degli Esposti, C., Bellini, M., and de Natale, P., 1994, J. Mol. Spec, 163, 521.

14. Christophorou, L.G. and Olthoff, J.K., 2004,

Fundamental Electron Interactions with Plasma Processing Gases,

Kluwer Academic/ Plenum Publishers New York.

15. Pabst, M.J.K., Tan, H.S., and Franklin, J.L., 1975, Int. J. Mass Spec. Ion Phys., $20,191$.

16. Chau, M., and Bowers, M.T., 1977, Int. J. Mass Spec. Ion Phys., 24, 191.

17. Jiao, C.Q., Nagpal, R., and Haaland, P.D., 1997, Chem. Phys. Letts., 269, 117.

18. Mayhew, C.A., Peverall, R., Timperley, C.M., and Watts, P., 2004 int. J. Mass Spectrometry, 233, 155.

19. Peverall, R., Kennedy, R.A., Mayhew, C.A., and Watts, P., 1997, Int. J. Mass Spec. Ion Proc., 171, 51.

20. Jarvis, G.K., Kennedy, R.A., Mayhew, C.A., and Tuckett, R.P., 2000, Int. J. Mass. Spectrom., 202, 323.

21. Howle, C.R., Mayhew, C.A., and Tuckett, R.P., 2005, J. Phys. Chem. A., 109, 3626.

22. Hatherly, P.A., Smith, D.M., and Tuckett, R.P., 1996, Zeit. Für Phys. Chem., $195,97$.

23. Powis, I., Mansell, P.I., and Danby, C.J., 1979, Int. J. Mass Spectrom. Ion Phys., 32, 15.

24. Jarvis, G.K., Seccombe, D.P., and Tuckett, R.P., 1999, Chem. Phys. Letts., 315, 287.

25. Howle, C.R., Collins, D.J., Tuckett, R.P., and Malins, A.E.R., 2005, Phys. Chem. Chem. Phys., 7, 2287.

26. Smith, D., and Adams, N.G., 1988, Adv. At. Mol. Phys., 24, 1.

27. Jarvis, G.K., Boyle, K.J., Mayhew, C.A., and Tuckett, R.P., 1998, J. Phys. Chem. A., 102, 3219

28. Traeger, J.C., and McLoughlin, R.G. 1981, J. Am. Chem. Soc., 103, 3647.

29. Zhou, W., Collins, D.J., Chim, R.Y.L., Seccombe, D.P. and Tuckett, R.P., 2004, Phys. Chem. Chem. Phys., 6, 3081.

30. Chase, M.W. 1998, J. Phys. Chem. Ref. Data, monograph no. 9 ; webbook.nist.gov/chemistry

31. Lias, S.G. Bartmess, J.E., Lebman, J.F., Holmes. J.L., Levin, R.D., and Mallard, W.G., 
1988, J. Phys. Chem. Ref. Data, 17, supplement no 1.

32. Garcia, G.A., Guyon, P.M., and Powis, I., 2001, J. Phys. Chem. A., 105, 8296.

33. Zhou, W., Seccombe, D.P., Tuckett, R.P., and Thomas, M.K., 2002, Chem. Phys., 283, 419.

34. Furuya, K., Matsuo, K., Maruyama, K., Hatano, Y., and Ogawa, T., 2002, J. Phys. B, 35, 1015.

35. Su, T., and Chesnavich, W.J., 1982, J. Chem. Phys, 76, 5183.

36. Langevin, P.M., 1905, Ann. Chim. Phys., 5, 245.

37. Gioumousis, G., and Stevenson, D.P., 1958, J. Chem. Phys., 29, 294.

38. Arnold, D.W., Bradforth, S.E., Kim, E.H., and Neumark, D.M., 1995, J. Chem. Phys., 102, 3493.

39. Duncan, T.V., and Miller, C.E., 2000, J. Chem. Phys., 113, 5138.

40. Irikura, K.K., 1999, J. Am. Chem. Soc., 121, 7689. 


\begin{tabular}{|c|c|c|c|c|}
\hline & $\mathrm{AE}_{298}{ }^{a}$ & $\Delta_{r} H^{0} 298, \exp { }^{b}$ & $\Delta_{r} H_{298, \text { calc }^{c}}$ & $\mathrm{AE}_{298, \text { calc }}{ }^{d}$ \\
\hline & $(\mathrm{eV})$ & $(\mathrm{eV})$ & $(\mathrm{eV})$ & $(\mathrm{eV})$ \\
\hline \multicolumn{5}{|l|}{ Major $^{e}$ products of $\mathrm{CHF}_{3}(-697)^{f}$} \\
\hline $\mathrm{CF}_{3}^{+}(+406)+\mathrm{H}(+218)+\mathrm{e}^{-}$ & $13.85 \pm 0.05$ & $13.96 \pm 0.05$ & 13.69 & 13.58 \\
\hline $\mathrm{CHF}_{2}^{+}(+604)+\mathrm{F}(+79)+\mathrm{e}^{-}$ & $15.03 \pm 0.05$ & $15.14 \pm 0.05$ & 14.30 & 14.19 \\
\hline \multicolumn{5}{|l|}{ Minor ${ }^{g}$ products of $\mathrm{CHF}_{3}(-697)$} \\
\hline $\mathrm{CF}^{+}(+1134)^{h}+\mathrm{HF}(-273)+\mathrm{F}(+79)+\mathrm{e}^{-}$ & $18.9 \pm 0.2$ & & 16.97 & \\
\hline
\end{tabular}

Experimentally derived appearance energies, measured from onset of signal above noise.

$b \quad$ Experimentally measured enthalpy of reaction, derived using the method of Traeger and McLoughlin [28].

$c \quad$ Calculated value for enthalpy of reaction given by enthalpy of formation of products minus that of reactants.

$d \quad$ Calculated appearance energy at $298 \mathrm{~K}$, derived using the method of Traeger and McLoughlin [28].

Major products are defined as fragments caused by breaking of a single bond.

$f \quad$ Literature values for $\Delta_{f} H^{0}{ }_{298}$ are given in $\mathrm{kJ} \mathrm{mol}^{-1}$ in brackets in column 1.

$g \quad$ Minor products are defined as fragments formed by breaking of more than one bond.

${ }_{h}$ Note that it is not possible energetically to form $\mathrm{CF}^{+}$with either $\mathrm{F}_{2}+\mathrm{H}+\mathrm{e}^{-}$or $2 \mathrm{~F}+\mathrm{H}+\mathrm{e}^{-} ; \Delta_{r} H^{0}{ }_{298}$ is calculated to be 21.24 and $22.87 \mathrm{eV}$, respectively. 
Table 2 Total mean kinetic energy releases $\left\langle\mathrm{KE}>_{\mathrm{T}}\right.$ of for the two-body fragmentation of valence states of $\mathrm{CHF}_{3}$.

\begin{tabular}{|c|c|c|c|c|c|c|c|}
\hline $\begin{array}{c}\text { Electronic State } \\
\text { of Parent Ion }\end{array}$ & $\begin{array}{l}\text { Daughter } \\
\text { Ion }\end{array}$ & $\begin{array}{l}\text { hv / } \\
\text { eV }\end{array}$ & $\begin{array}{c}E_{\text {avail }}{ }^{a} / \\
\mathrm{eV}^{2}\end{array}$ & $\begin{array}{c}<\mathrm{KE}>_{\mathrm{t}} / \\
\mathrm{eV}\end{array}$ & $\underset{\text { experimental }^{b}}{<>_{\mathrm{t}}}$ & $\begin{array}{c}\quad\langle f\rangle_{\mathrm{t}} \\
\text { statistical }\end{array}$ & $\begin{array}{c}\langle f\rangle_{\mathrm{t}} \\
\text { impulsive }\end{array}$ \\
\hline $\mathrm{CHF}_{3}^{+} \tilde{X}^{2} \mathrm{~A}_{1}$ & $\mathrm{CF}_{3}^{+}$ & 14.76 & 1.24 & $0.66(9)$ & 0.53 & 0.10 & 0.94 \\
\hline$\widetilde{B}^{2} \mathrm{E}$ & $\mathrm{CHF}_{2}^{+}$ & 16.35 & 2.22 & $1.02(4)$ & 0.46 & 0.10 & 0.53 \\
\hline$\widetilde{C}^{2} \mathrm{E}$ & $\mathrm{CHF}_{2}^{+}$ & 17.36 & 3.23 & $1.18(3)$ & 0.37 & 0.10 & 0.53 \\
\hline
\end{tabular}

$a \quad E_{\text {avail }}=\mathrm{hv}+$ thermal energy of parent molecule at $298 \mathrm{~K}(0.06 \mathrm{eV})-\mathrm{AE}_{298, \text { calc. }}$ See text.

b Given by $<\mathrm{KE}>_{\mathrm{t}} / E_{\text {avail }}$. 
Table 3 Rate coefficients at $298 \mathrm{~K}$, product cations and branching ratios, and suggested neutral products ${ }^{a}$ for reactions of gas-phase cations with $\mathrm{CHF}_{3}$. The calculated enthalpy of reaction at $298 \mathrm{~K}$ is shown in the fifth column.

\begin{tabular}{|c|c|c|c|c|}
\hline $\begin{array}{l}\text { Reagent ion } \\
\left(\mathrm{RE}^{b} / \mathrm{eV}\right)\end{array}$ & $\begin{array}{l}\text { Rate coefficient }{ }^{c} / \\
10^{-9} \mathrm{~cm}^{3} \text { molecule }^{-1} \\
\mathrm{~s}^{-1}\end{array}$ & Product ions (\%) & $\begin{array}{l}\text { Proposed neutral } \\
\text { products }\end{array}$ & $\begin{array}{l}\Delta_{r} H_{298}^{\mathrm{o}} \\
\mathrm{kJ} \mathrm{mol}^{-1}\end{array}$ \\
\hline $\begin{array}{l}\mathrm{H}_{3} \mathrm{O}^{+} \\
(6.27)\end{array}$ & {$\left[\begin{array}{c}- \\
{[2.3]}\end{array}\right.$} & No Reaction ${ }^{d}$ & - & - \\
\hline $\begin{array}{l}\mathrm{SF}_{3}^{+} \\
(8.32)\end{array}$ & - & No Reaction & - & - \\
\hline $\begin{array}{l}\mathrm{CF}_{3}^{+} \\
(9.04)\end{array}$ & $\begin{array}{c}0.4 \\
{[1.5]}\end{array}$ & $\mathrm{CHF}_{2}^{+}(100)$ & $\mathrm{CF}_{4}$ & -38 \\
\hline $\begin{array}{l}\mathrm{CF}^{+} \\
(9.11)\end{array}$ & $\begin{array}{c}1.3 \\
{[1.9]}\end{array}$ & $\mathrm{CHF}_{2}^{+}(100)$ & $\mathrm{CF}_{2}$ & -15 \\
\hline $\begin{array}{l}\mathrm{NO}^{+} \\
(9.26)\end{array}$ & {$\left[\begin{array}{c}- \\
{[2.0]}\end{array}\right.$} & No Reaction & - & - \\
\hline $\begin{array}{l}\mathrm{SF}_{5}^{+} \\
(9.78)\end{array}$ & - & No Reaction & - & - \\
\hline $\begin{array}{c}\mathrm{SF}_{2}^{+} \\
(10.24)\end{array}$ & $\begin{array}{c}- \\
{[1.5]}\end{array}$ & No Reaction & - & - \\
\hline $\begin{array}{c}\mathrm{SF}^{+} \\
(10.31)\end{array}$ & - & No Reaction & - & - \\
\hline $\begin{array}{l}\mathrm{CF}_{2}^{+} \\
(11.44)\end{array}$ & $\begin{array}{c}1.4 \\
{[1.7]}\end{array}$ & $\mathrm{CHF}_{2}^{+}(100)$ & $\mathrm{CF}_{3}$ & -87 \\
\hline $\begin{array}{l}\mathrm{SF}_{4}^{+} \\
(11.99)\end{array}$ & $\begin{array}{c}- \\
{[1.4]}\end{array}$ & No Reaction & - & - \\
\hline $\begin{array}{c}\mathrm{O}_{2}^{+} \\
(12.07)\end{array}$ & - & No Reaction & - & - \\
\hline $\begin{array}{c}\mathrm{Xe}^{+} \\
(12.13)\end{array}$ & - & No Reaction & - & - \\
\hline $\begin{array}{l}\mathrm{H}_{2} \mathrm{O}^{+} \\
(12.62)\end{array}$ & $\begin{array}{c}1.5 \\
{[2.4]}\end{array}$ & $\mathrm{CF}_{2} \mathrm{OH}^{+}(100)$ & $\mathrm{HF}+\mathrm{H}$ & -102 \\
\hline $\begin{array}{l}\mathrm{N}_{2} \mathrm{O}^{+} \\
(12.89)\end{array}$ & - & No reaction & - & - \\
\hline $\begin{array}{c}\mathrm{OH}^{+} \\
(13.25)\end{array}$ & $\begin{array}{c}2.2 \\
{[2.4]}\end{array}$ & $\mathrm{CHF}_{2}^{+}(68)^{e}$ & $\begin{array}{c}\mathrm{HOF} \\
\mathrm{HF}+\mathrm{O}\end{array}$ & $\begin{array}{l}-90 \\
-15\end{array}$ \\
\hline
\end{tabular}




\begin{tabular}{|c|c|c|c|c|}
\hline & & $\mathrm{CF}_{3}^{+}(32)^{e}$ & $\mathrm{H}_{2} \mathrm{O}$ & -432 \\
\hline $\begin{array}{c}\mathrm{O}^{+} \\
(13.62)\end{array}$ & $\begin{array}{c}2.5 \\
{[2.4]}\end{array}$ & $\mathrm{CHF}_{2}^{+}(100)$ & OF & -153 \\
\hline $\begin{array}{c}\mathrm{CO}_{2}^{+} \\
(13.76)\end{array}$ & $\begin{array}{c}0.4 \\
{[1.7]}\end{array}$ & $\begin{array}{l}\mathrm{CHF}_{2}^{+}(55) \\
\mathrm{CF}_{3}^{+}(45)\end{array}$ & $\begin{array}{c}\mathrm{FOCO} \\
\mathrm{HOCO} \\
\text { or } \mathrm{CO}_{2}+\mathrm{H}\end{array}$ & $\begin{array}{c}10 \\
-11 \\
-8\end{array}$ \\
\hline $\begin{array}{c}\mathrm{Kr}^{+} \\
\left(14.00(\& 14.67)^{f}\right)\end{array}$ & $\begin{array}{c}0.8 \\
{[1.5]}\end{array}$ & $\begin{array}{l}\mathrm{CHF}_{2}^{+}(16) \\
\mathrm{CF}_{3}^{+}(84)\end{array}$ & $\begin{array}{l}\mathrm{Kr}+\mathrm{F} \\
\mathrm{Kr}+\mathrm{H}\end{array}$ & $\begin{array}{l}30(\text { or }-35)^{f} \\
-30(\text { or }-95)^{f}\end{array}$ \\
\hline $\begin{array}{c}\mathrm{CO}^{+} \\
(14.01)\end{array}$ & $\begin{array}{l}2.0 \\
{[2.0]}\end{array}$ & $\begin{array}{c}\mathrm{CHF}_{2}^{+}(97) \\
\mathrm{CF}_{3}^{+}(3)\end{array}$ & $\begin{array}{l}\mathrm{CO}+\mathrm{F} \\
\text { or } \mathrm{FCO} \\
\mathrm{CO}+\mathrm{H} \\
\text { or } \mathrm{HCO}\end{array}$ & $\begin{array}{c}29 \\
-112 \\
-30 \\
-95\end{array}$ \\
\hline $\begin{array}{c}\mathrm{N}^{+} \\
(14.53)\end{array}$ & $\begin{array}{c}2.3 \\
{[2.6]}\end{array}$ & $\begin{array}{l}\mathrm{CHF}_{2}^{+}(61) \\
\mathrm{CF}_{3}^{+}(39)\end{array}$ & $\begin{array}{l}\mathrm{N}+\mathrm{F} \\
\text { or } \mathrm{NF} \\
\mathrm{N}+\mathrm{H} \\
\text { or } \mathrm{NH}\end{array}$ & $\begin{array}{l}-22 \\
-96 \\
-81 \\
-395\end{array}$ \\
\hline $\begin{array}{c}\mathrm{N}_{2}^{+} \\
(15.58)\end{array}$ & $\begin{array}{l}2.1 \\
{[2.0]}\end{array}$ & $\begin{array}{l}\mathrm{CHF}_{2}^{+}(46) \\
\mathrm{CF}_{3}^{+}(54)\end{array}$ & $\begin{array}{l}\mathrm{N}_{2}+\mathrm{F} \\
\mathrm{N}_{2}+\mathrm{H}\end{array}$ & $\begin{array}{l}-123 \\
-182\end{array}$ \\
\hline $\begin{array}{c}\mathrm{Ar}^{+} \\
(15.76)\end{array}$ & $\begin{array}{c}1.8 \\
{[1.8]}\end{array}$ & $\begin{array}{l}\mathrm{CHF}_{2}^{+}(72) \\
\mathrm{CF}_{3}^{+}(28)\end{array}$ & $\begin{array}{l}\mathrm{Ar}+\mathrm{F} \\
\mathrm{Ar}+\mathrm{H}\end{array}$ & $\begin{array}{l}-141 \\
-200\end{array}$ \\
\hline $\begin{array}{c}\mathrm{F}^{+} \\
(17.42)\end{array}$ & $\begin{array}{c}1.9 \\
{[2.3]}\end{array}$ & $\mathrm{CHF}_{2}^{+}(100)$ & $\begin{array}{l}F+F \\
\text { or } F_{2}\end{array}$ & $\begin{array}{l}-300 \\
-459\end{array}$ \\
\hline $\begin{array}{c}\mathrm{Ne}^{+} \\
(21.56)\end{array}$ & $\begin{array}{c}1.9 \\
{[2.2]}\end{array}$ & $\begin{array}{l}\mathrm{CHF}_{2}^{+}(7) \\
\mathrm{CF}_{2}^{+}(15) \\
\mathrm{CF}^{+}(78)\end{array}$ & $\begin{array}{c}\mathrm{Ne}+\mathrm{F} \\
\mathrm{Ne}+\mathrm{HF} \\
\mathrm{Ne}+\mathrm{HF}+\mathrm{F}\end{array}$ & $\begin{array}{l}-700 \\
-734 \\
-442\end{array}$ \\
\hline
\end{tabular}

The majority of the enthalpies of formation at $298 \mathrm{~K}$ for ion and neutral species are taken from standard sources [30,31]. Exceptions are more recent experimental values for $\mathrm{CF}_{3}, \mathrm{CF}_{3}{ }^{+}$[32], and $\mathrm{CHF}_{2}^{+}$[33]. For neutral FOCO and HOCO, we use experimental and $a b$ initio values, respectively, for their lower trans isomer of -356 and $-179 \mathrm{~kJ} \mathrm{~mol}^{-1}[38,39]$. Recombination energy (RE) of reactant ion. For molecular ions, the $\mathrm{RE}$ is given for $v=0$. For atomic ions, the RE is given for the lower spin-orbit component, where appropriate. The one exception is $\mathrm{Kr}^{+}$where the RE is given for both ${ }^{2} \mathrm{P}_{3 / 2}$ and ${ }^{2} \mathrm{P}_{1 / 2}$ components (see text) The values in square brackets are calculated by the Modified Average Dipole Orientation model [35], using literature values for the dipole moment $(1.65 \mathrm{D})$ and polarisability volume $\left(3.15 \times 10^{-30} \mathrm{~m}^{3}\right)$ of $\mathrm{CHF}_{3}$ [14].

$d \quad$ No reaction means the rate coefficient is less than $c a \cdot 10^{-13} \mathrm{~cm}^{3}$ molecule $\mathrm{s}^{-1}$.

$e \quad$ There is also a trace $(<1 \%)$ of product with mass $87 \mathrm{u}, \mathrm{OH}^{e} \cdot . . \mathrm{CHF}_{3}{ }^{+}$, from this reaction.

$f \quad$ Values in brackets refer to $\mathrm{Kr}^{+}$in its excited spin-orbit state 


\section{Figure Captions}

Figure 1. (a) Threshold photoelectron spectrum of $\mathrm{CHF}_{3}$ recorded on beamline 3.2 at a resolution of $0.15 \mathrm{~nm}$. (b) TPEPICO coincidence ion yields of $\mathrm{CF}_{3}{ }^{+}, \mathrm{CHF}_{2}{ }^{+}$and $\mathrm{CF}^{+}$recorded on beamline 3.1 at a resolution of $0.3 \mathrm{~nm}$.

Figure 2. Time of flight spectrum (dots) for the $\mathrm{CHF}_{2}{ }^{+}$fragment ion produced from dissociative photoionisation of $\mathrm{CHF}_{3}$ at a photon energy of $17.36 \mathrm{eV}$. The solid line is the best fit, using the procedure described elsewhere [23,24]. The total, average translational kinetic energy release, $\left\langle\mathrm{KE}>_{\mathrm{t}}\right.$, is determined to be $1.18 \pm 0.03 \mathrm{eV}$, corresponding to $37 \%$ of the available energy.

Figure 3. Comparison of the ionic products from ion-molecule studies of $\mathrm{CHF}_{3}$ with TPEPICO photoionisation branching ratios over the energy range $14-25 \mathrm{eV}$. The half-filled symbols at $14.67 \mathrm{eV}$ correspond to $\mathrm{Kr}^{+}$in its excited ${ }^{2} \mathrm{P}_{1 / 2}$ spin-orbit component. 
Figure 1

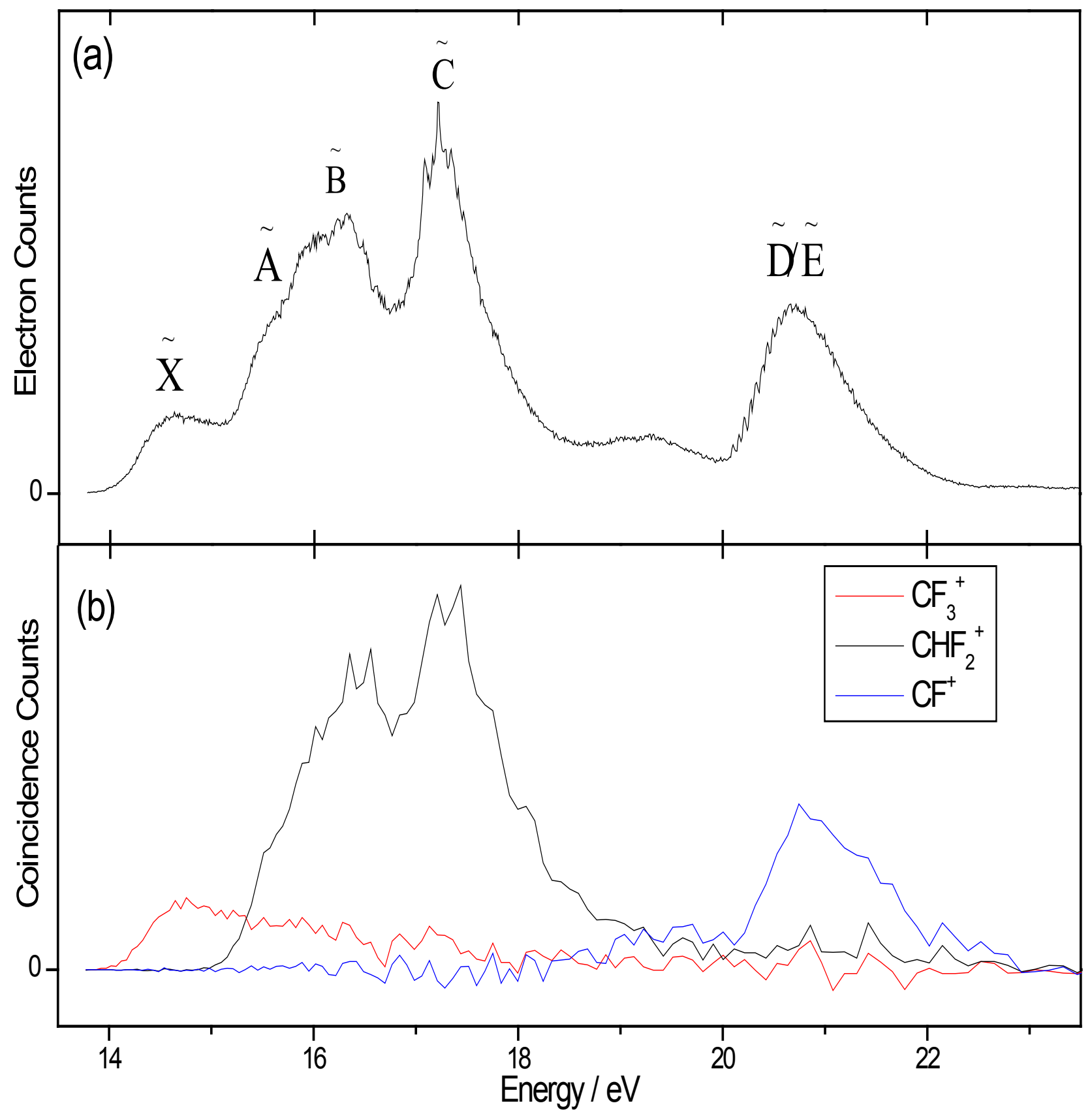


Figure 2

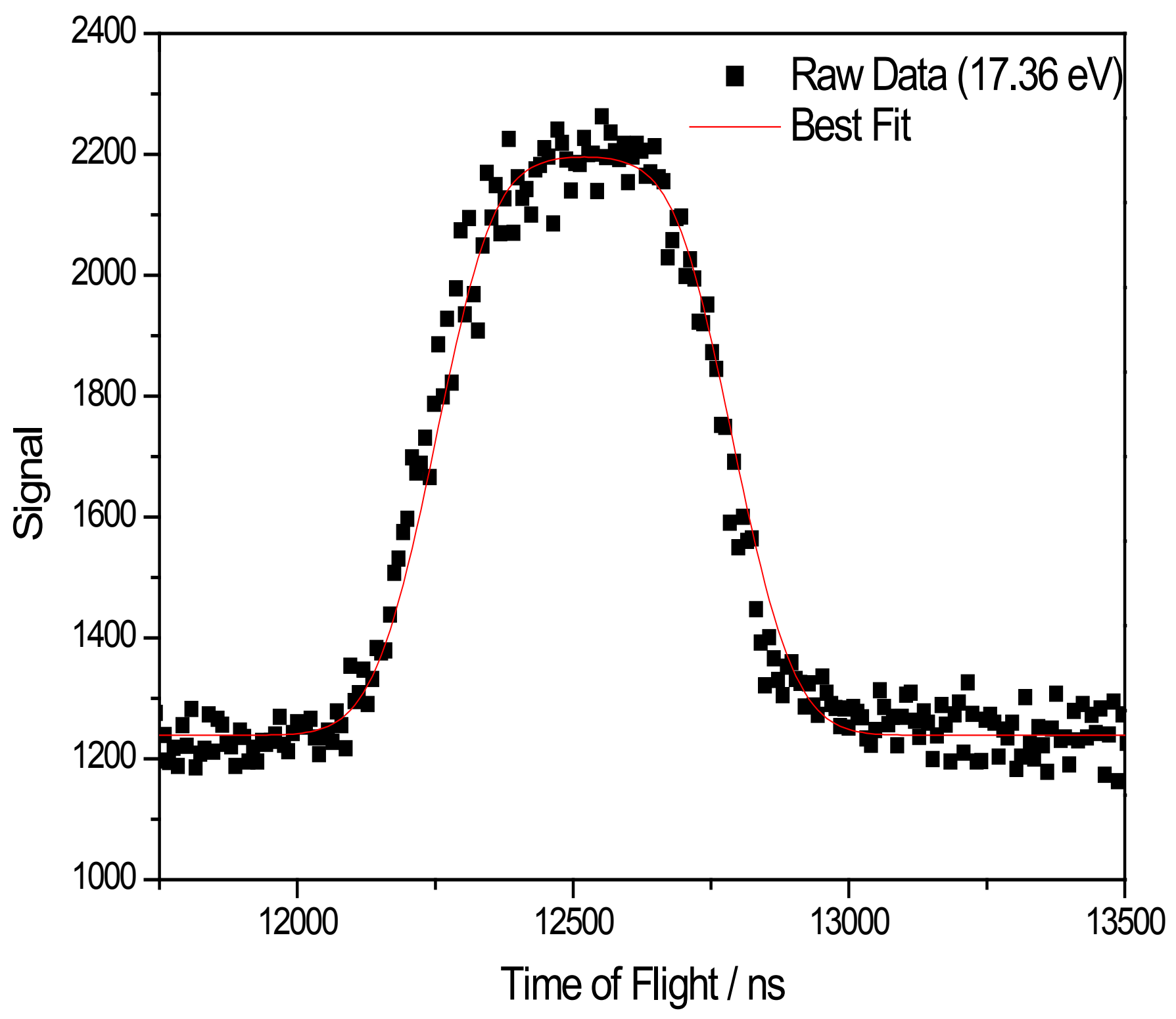


Figure 3

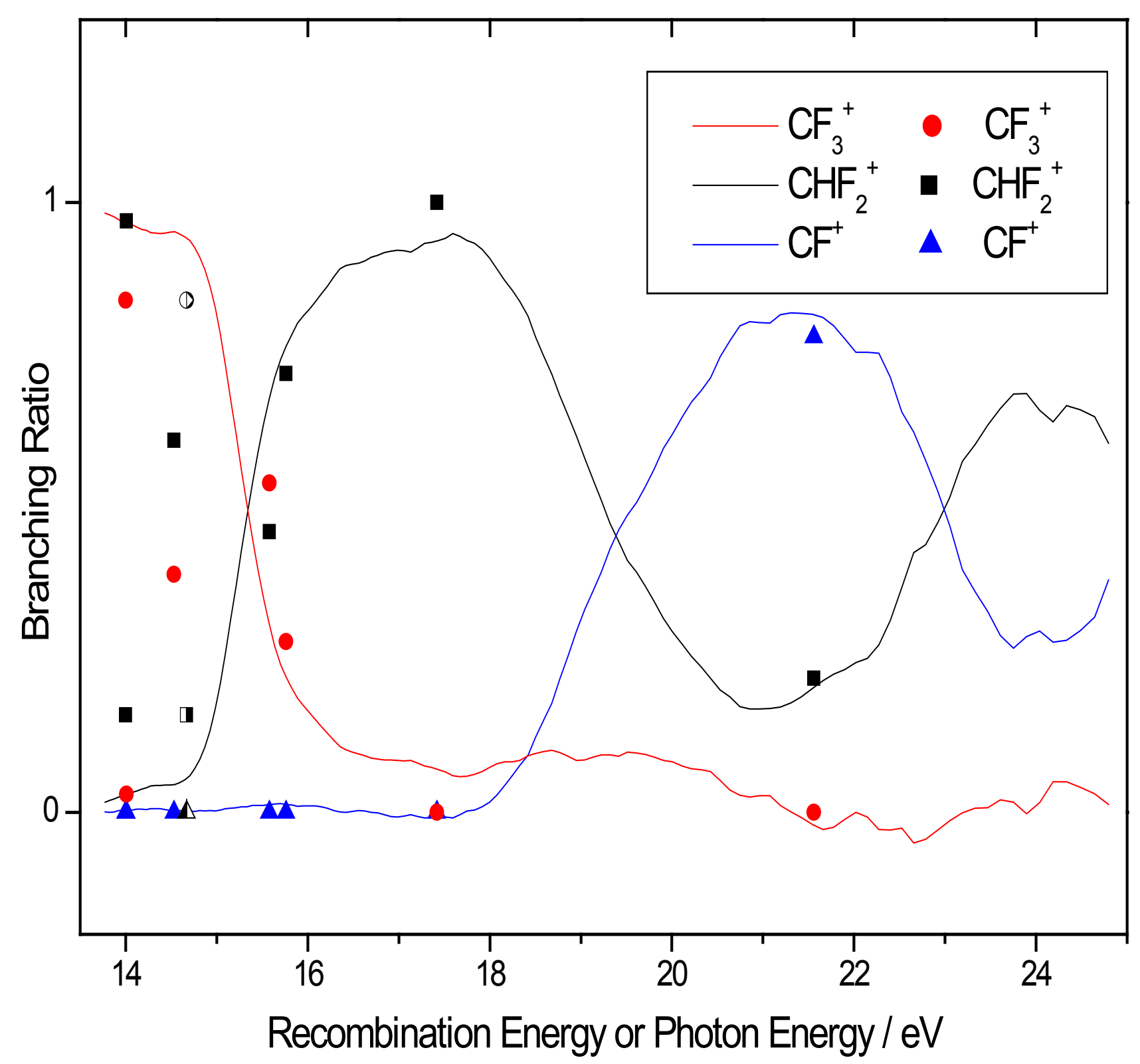

